\title{
A Novel Outcome-Based Educational Model and its Effect on Student Learning, Curriculum Development, and Assessment
}

\author{
Faouzi Bouslama, Azzedine Lansari, Akram Al-Rawi, \\ and Abdullah A. Abonamah \\ Zayed University, Abu Dhabi, UAE
}

\author{
Faouzi.bouslama@zu.ac.ae Azzedine.lansari@zu.ac.ae \\ Akram.alrawi@zu.ac.ae Abdullah.abonamah@zu.ac.ae \\ Executive Summary
}

In this paper, a new academic model that responds to the challenges of a modern society such as the UAE is proposed. This academic model is hybrid as it is outcome driven and also uses the traditional grade point average (GPA). The learning outcomes are used at all stages of the students' academic life. These outcomes are derived from the university's vision of the knowledge and skills that students need to acquire in order to be life-long learners. The framework that constitutes the academic model is composed of the following components: course embedded and higher-order learning outcomes; students and faculty equipped with laptops and campus wide networked classrooms; a center for teaching and learning assessment; and learning communities. These learning communities are responsible for reviewing and modifying the Academic Program Model, and include members from both inside and outside the university. In the final stage of their education, students develop electronic portfolios (e-portfolios) to demo nstrate their achievements. This paper shows how technology can be used to facilitate the learning and assessment processes and how assessment is used to make the learning outcomes component work effectively. It also describes how learning outcomes are used in the development of an information systems curriculum.

Keywords: Outcome based learning, Academic Program Model, Learning outcomes, e-portfolio, Assessment.

\section{Introduction}

We live in a rapidly changing world driven by technology and economy necessitating the production of qualified and well-prepared professionals. Employers are demanding that university graduates not only have the knowledge, but the appropriate skills to be effective and productive in the workplace. In order to adapt to these challenges, universities worldwide are thinking about how to redesign their academic models. A recent US national panel report calls for a dramatic reorganization of undergraduate education to ensure that all college students receive not just access to college, but an education of lasting

Material published as part of this journal, either on-line or in print, is copyrighted by the publisher of the Journal of Information Technology Education. Permission to make digital or paper copy of part or all of these works for personal or classroom use is granted without fee provided that the copies are not made or distributed for profit or commercial advantage AND that copies 1) bear this notice in full and 2) give the full citation on the first page. It is permissible to abstract these works so long as credit is given. To copy in all other cases or to republish or to post on a server or to redistribute to lists requires specific permission and payment of a fee. Contact Editor@ JITE.org to request redistribution permission. value. The report also recommends colleges help students become "intentional" life-long learners, and to create new assessments that require students to apply their learning to the real world (Greater Expectation, 2002).

Zayed University (ZU), a laptop university (each student and faculty owns a laptop) based in the United Arab Emirates, has adopted a new educational concept in the region, which is an OutcomeBased learning approach. This new Academic 
Program Model (APM) is designed to continuously improve the curriculum and provide students with the knowledge and skills to succeed in a rapidly changing world. The life-long learning outcomes, being the kernel of the courses, provide focus to the curriculum in the APM. Furthermore, all courses are designed to clearly show the experiences that students draw upon achieving a Learning Outcome. The ZU OBE learning approach is framed by three sets of learning outcomes. Two are course embedded (general education and major learning outcomes), and the third (the ZU learning outcomes (ZULO)) is a set of higher intellectual outcomes. To fulfill their ZULO requirements, students compile evidence of their achievement in electronic portfolios, which are assessed by a faculty panels. The APM is driven by five critical components: the outcome based curriculum, the e-portfolios, the learning communities, the use of information technology, and the support of the center for teaching and learning assessment.

Universities in the USA and worldwide are taking a critical look at their educational systems. A recent US national panel report calls for a dramatic reorganization of undergraduate education to ensure that all college aspirants receive not just access to college, but an education of lasting value. The report also recommends colleges help students become "intentional" life-long learners, and to create new assessments that require students to apply their learning to the real world (Greater Expectation, 2002). Furthermore, universities in the US and worldwide are complaining about the problem of grade inflation (Rosovsky \& Hartley, 2002).

A number of academic institutions in the US have moved to an outcome-based education framework to move away from the grade point average driven academic framework. In North America, accreditations institutions (such as North Central Association) are asking academic institutions to present a method to assess students learning outcomes in the general education courses. In Columbia College, Columbia, Missouri, assessment of the student learning outcomes in the Information Literacy course is done by giving them a pre-test and a post-test. During the first day of the course, students are given a multiplechoice test about computer literacy. The same test is given to the students during the last week of the course as part of their final examination. The difference between the two grades is used as a measure of their progress.

A new academic institution in the gulf region has tackled the above issues by adopting an academic framework that is based on the outcome-based education while still using the grade point average. This academic model is a hybrid approach that accommodates learning outcomes to measure the learning process and uses grades to accommodate the classic academic system. We anticipate that this model will insure that grade inflation is under control and that students are achieving the learning outcomes to become life-long learners (Bouslama, Lansari, Al-Rawi, \& Abonamah, 2002).

The rest of this paper is organized as follows. The first section gives an overview of outcome-based education. The second section introduces the ZU academic program model. The third section provides information on the implementation of the ZU APM. The fourth section presents the college of information systems hybrid curriculum. Finally, the last section provides conclusions.

\section{Outcome-Based Education Overview}

Outcome-based education is a method of teaching that focuses on what students can actually do after they are taught. All curriculum and teaching decisions are made based on how best to facilitate the desired outcome. This leads to a planning process that is different from the traditional educational planning. The desired outcome is first identified and the curriculum is created to support the intended outcome (Fitzpatrick, 1995; Furman, 1994).

There is no single authoritative model for Outcome-Based Education (OBE). Frameworks for OBE share an emphasis on systems-level change, observable, measurable outcomes, and the belief that given time all students can learn. The shift toward OBE is a result of educational institutions worries about the current education system (Glatthorn, 1993; Guskey, 1994). There is a belief in the academic world that 
the classic "input" educational system can not adequately prepare students for life and work in the twenty first century. Consequently, educators and policy makers are attempting to modify the way to measure the effectiveness of education. There is a need to shift from the emphasis on traditional inputs, such as course credits earned and hours spent in class to outcomes (Greater Expectation, 2002).

Learning outcomes are to be clear, observable demonstrations of student learning that occur after a significant set of learning experiences. They are not values, attitudes, feelings, beliefs, activities, assignments, goals, or grades, as many people tend to believe. Typically, these demonstrations, or performances, reflect three things: (1) what the student knows; (2) what the student can actually do with what s/he knows; and (3) the student's confidence and motivation in demonstrating what s/he knows (Guskey, 1994; Kirk, \& Welborn, 1992; McNeir, 1993).

Proponents of OBE agree that even though there are many ways to arrive at the same results, what is important is that students achieve the defined outcomes. Opponents worry about why and how outcomes are selected and how students and schools are held accountable for achieving these outcomes. Both sides raise critical points on the structure and direction of the education system and the primary role of education in the community. There is some fear by educators that OBE takes away the freedom that teachers have in decision making pertaining to course content, course delivery and assessment. The fear of losing control of their courses has created a phobia of OBE (Schwarz \& Cavener, 1994; Spady \& Marshall, 1994).

Universities in the Middle East and North Africa are using the classical educational system. However, ZU in the United Arab Emirates (UAE) has adopted a hybrid educational framework that uses both learning outcomes and GPA in its academic model. The ZU Academic Program Model (ZU APM) was developed to address challenges that face a rapidly changing society such as the UAE. The academic program was designed to help graduates face a complex challenging world. Following the first year, educators and administrators agreed that it is virtually impossible for a person to master a discipline or professional field without an emphasis on "Life-long Learning" rather than simply acquiring knowledge. The new Learning Outcome Academic model was developed to focus on the process of learning and was designed to help students develop critical intellectual capacities and skills (Academic Program Model, 2002).

The ZU learning outcome model is a unique educational framework that draws on resources from the learning communities within and outside the institution. Furthermore, the learning communities are actively involved in shaping the model to make sure it addresses the needs of the country. In the following section, the ZU Academic Program Model is introduced.

\section{The ZU Academic Program Model}

The ZU Academic Program Model is designed to serve as the underlying structure that guides faculty and students in the development of ZU programs. The learning outcomes, the learning communities, the e-portfolio, and the wired and laptop based campus form the infrastructure that supports the ZU APM as shown in Figure 1.

The ZU academic program model includes learning outcomes at all stages in the student's academic life. The curriculum at ZU involves three main programs:

- The readiness program

- The general education

- The degree majors programs

The readiness program is a prerequisite for students to be admitted to general education. Students must satisfy competency in English, basic mathematics and information technology. Students spend two years 


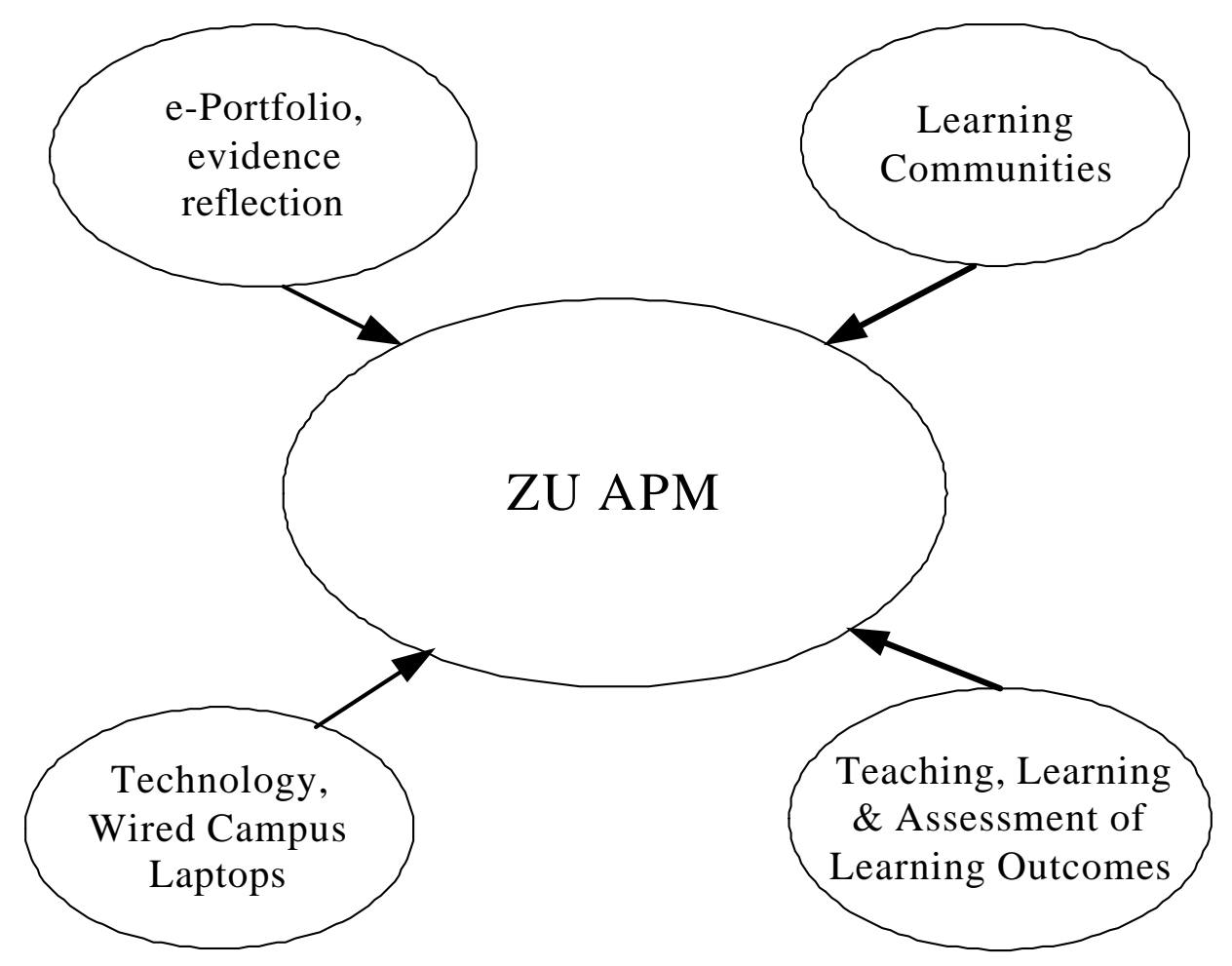

Figure 1. Components of the ZU Academic Program Model

in the general education program and the last two years in a major of their choice. All students are assigned a seminar advisor upon joining the university.

After entering their majors, students are assigned a major advisor. Students, with the assistance of their advisors, develop an individual learning plan. Learning outcomes in the major colleges emphasize planning, decision-making, and application skills, and students are assessed for their ability to demonstrate applied synthesis and integration of knowledge and skills.

The ZU APM is framed by three sets of learning outcomes, as shown in Figure 2:

- The General Education Learning Outcomes (GELO)

- The Major Learning Outcomes (MALO)

- The ZU Learning Outcomes (ZULO)

The GELOs and MALOs are course embedded, and the ZULOs are a set of higher intellectual outcomes, which can be achieved at different levels of the students' learning experiences.

\section{The ZU APM Learning Outcomes}

The GELOs are designed to help students develop an understanding and the ability to apply the theoretical structures and methodologies of the academic disciplines. There are five GELOs: Creative Expression, Culture and Society, Humanities, Language and Communication and Science, Mathematics and Technology. The GELO knowledge domains are defined as follows:

- Creative Expression: Graduates will make artistic form and observe, analyze and reflect on the many dimensions of human experience. 


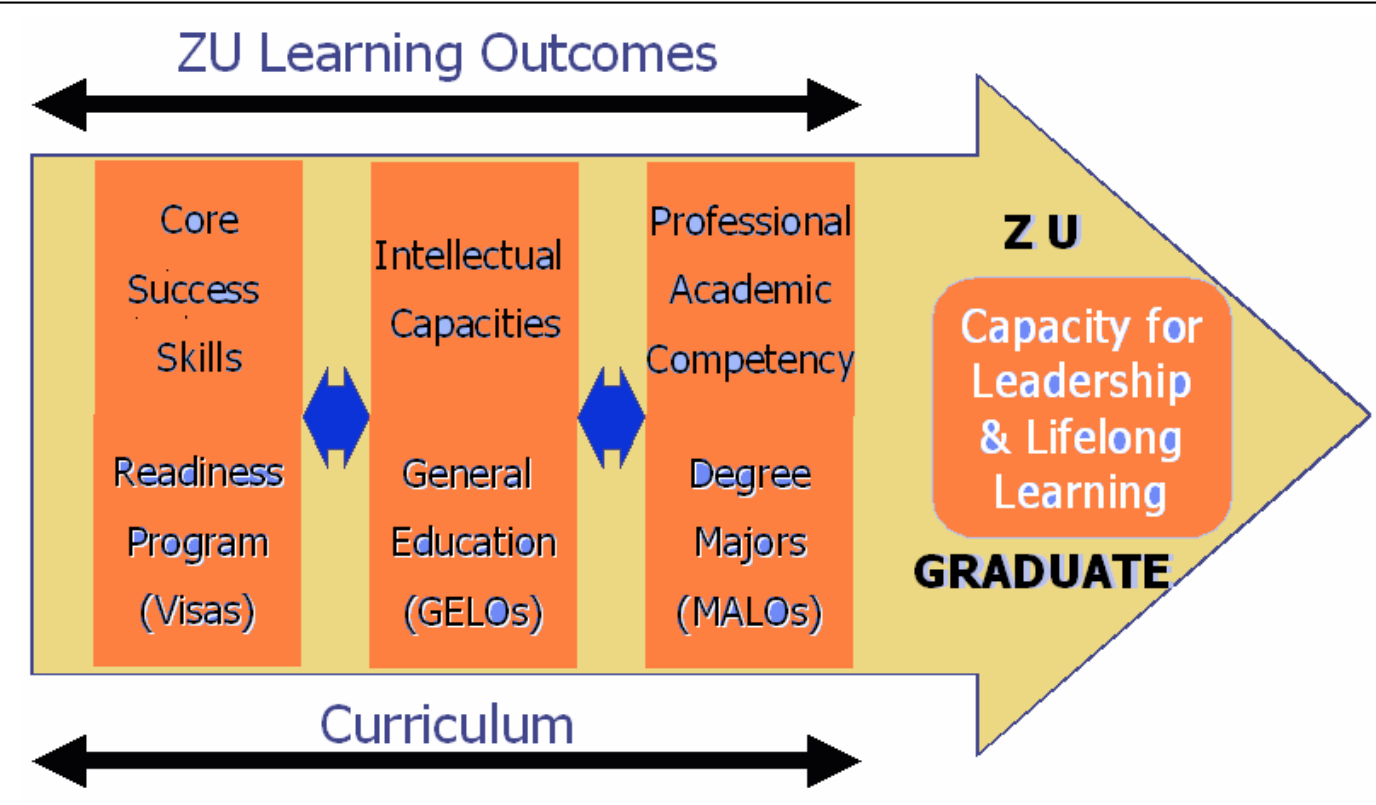

Figure 2. ZU Academic Program Model

- Culture and Society: Graduates will examine and discuss cultural and social issues from multiple perspectives; explore the relationships between different cultures on issues such as economics, politics, psychology, social history, sociology, and technology; identify cultural values and assumptions in different communities; investigate the development of their own cultural values; and appreciate the impact of human society on nature.

- Humanities: Graduates will develop an understanding of the history and culture of human experience, enrich the mind and contribute to the development of a more humane world.

- Language and Communication: Graduates will communicate effectively in English and Arabic. They will read and listen to comprehend a wide range of written and spoken information, and write and speak effectively in a variety of contexts using diverse media.

- Science, Mathematics and Technology: Graduates will use the tools and methodologies of science, mathematics, and technology and their interaction to solve problems and explain the world in a wide environmental, cultural, social and economic context.

The above GELOs specify what students should be able to achieve by studying the subjects in a specific knowledge domain. For example studying in Science, Mathematics, and Technology domain should enable the student to comprehend and apply the scientific method as a tool for thinking and seeking knowledge.

The MALOs are designed to help students develop academic and professional competencies necessary to function effectively and independently as a scholar and practitioner in a selected field. MALOs are developed in their respective colleges. The College of Information Systems (CIS), for example, has established five MALOs that complement the learning outcomes of the ZU Academic program model. These MALOs form the basis for analysis and assessment that play an essential role in the continuous process of improvement. The MALOs for the College of Information Systems are:

- Problem identification and analysis: Graduates will be able to recognize, define, and classify problems.

- Problem solving: Graduates will derive solutions and evaluate their success. 
- Internet technologies and applications: Graduates will understand the capabilities, use, and application of information technology.

- Systems principles and practices: Graduates will demonstrate understanding of system types, structures, standards and metrics.

- Technical communication: Graduates will organize, develop, present and evaluate technical material.

There are six ZU Learning Outcomes (ZULOs), which are the over-arching requirements for students to graduate from their major. ZULOs identify five critical areas that are significant for students. These are: Critical Thinking and Reasoning, Information Literacy and Communication, Information Technology, Global Awareness, Teamwork and Leadership. During their last semester students need to participate in the internship program and complete a capstone project (Academic Program Model, 2002).

ZULOs, which form the framework for the APM, are designed to help students develop higher order intellectual abilities needed for life-long learning and success. All students must demonstrate accomplishments in the following ZULOs before they graduate:

- Information Literacy and Communication: Students who graduate will be able to recognize information needs, access and evaluate appropriate information to answer those needs, and communicate effectively to a variety of audiences in English and Arabic

- Information Technology: Graduates will be able to use information technology to solve problems and communicate in an ethical way. They will also be critically aware of the impact of information technology on the individual and society.

- Critical Thinking and Reasoning: Graduates will be able to use information, reasoning, and creative processes to achieve goals and make responsible decisions.

- Global Awareness: Graduates will be able to relate to communities beyond the local, perceive and react to differences from an informed and reasoned point of view, and be critically aware of implications and benefits of cultural interactions

- Teamwork: Graduates will be able to work efficiently and effectively in a group.

- Leadership: Graduates will be able to assume leadership roles and responsibilities in a variety of life situations and accept accountability for the results.

In the following section, we explain how the ZU APM is implemented. We introduce the Center of Teaching and Learning Assessment, the Learning Outcome Assessment courses, the student and faculty training, the e-portfolio and how the learning outcomes are used in the Internship and Capstone project.

\section{Implementation of the ZU Academic Program Model}

The successful implementation of the ZU APM requires the contribution of faculty, students, staff and the community at large. ZU created a training center, the Center for Teaching, Learning and Assessment (CTLA), to support and coordinate faculty members in the process of understanding, implementing and teaching learning outcomes. The center also supports students in their understanding of the learning outcomes and development of their electronic portfolio (e-Portfolio). Finally, the colleges advance the process of learning by ensuring that students use learning outcomes in their Internship experiences and capstone projects. 


\section{The Center of Teaching, Learning and Assessment (CTLA)}

The CTLA is a support center for faculty and students that coordinates the functions and services related to the implementation of the ZU APM. The CTLA also manages the ZU learning outcome assessment process. The objective of the center is to ensure that the assessment of the learning outcomes leads to continuous improvement of the ZU APM model and student learning.

The CTLA works with the faculty and students to achieve the following:

- Coordinate and document learning assessments

- Coordinate the training of assessors

- Assist students and faculty with issues related to learning outcomes assessment process.

- Communicate regularly with all concerned parties such as faculty, students, learning communities and administrators to provide information on the performance of APM and ensure the inte grity of the model.

- Conduct formative program assessment and action research.

\section{The Learning Outcome Assessment Courses and Student Training}

The Learning Outcomes Assessment (LOA) courses are designed to help students learn about the outcomes, identify pieces of evidence to show achievement, and develop a portfolio that exhibits their work and reflection. The principles guiding the learning assessme nt process assume that life-long learning is fostered through self-assessment and reflection. Furthermore, the purpose of assessment is focused on student learning where they are expected to participate actively in the assessment of their own learning and are continuously provided with feedback from faculty.

The following procedures are associated with the Learning Outcome assessment process:

- Common indicators, criteria and developmental level standards are used across the University to assess the ZU Learning Outcomes.

- Colleges set minimum ZU Learning Outcomes developmental level standards for entrance to the internship and for graduation.

- Students must satisfy ZU Learning Outcomes as a condition for entry into their internship and to graduate. There are two points of formal student assessment for satisfaction of ZU Learning Outcomes:

- Before internship (as a condition for registration in internship)

- Before graduation (as a condition for graduation).

- The University through the Office of the Provost certifies that students have satisfied ZU Learning Outcomes requirements for enrollment in internship and for graduation.

- ZU Learning Outcomes assessors must be certified. The assessor certification program includes:

○ Orientation to the ZU philosophy and principles of learning assessment.

o Normalizing learning outcomes, indicators, and criteria to establish consistent expectations for all University students.

- Preparing narrative reports of student performance results.

o Providing constructive feedback and guidance to students.

- ZU Learning Outcomes assessment is documented in an e-portfolio by students and certified ZU Learning Outcomes assessors. 
- Final assessment reports are official University records maintained by the Office of the Provost.

- Students must establish e-portfolios (for technical reasons) through the CTLA.

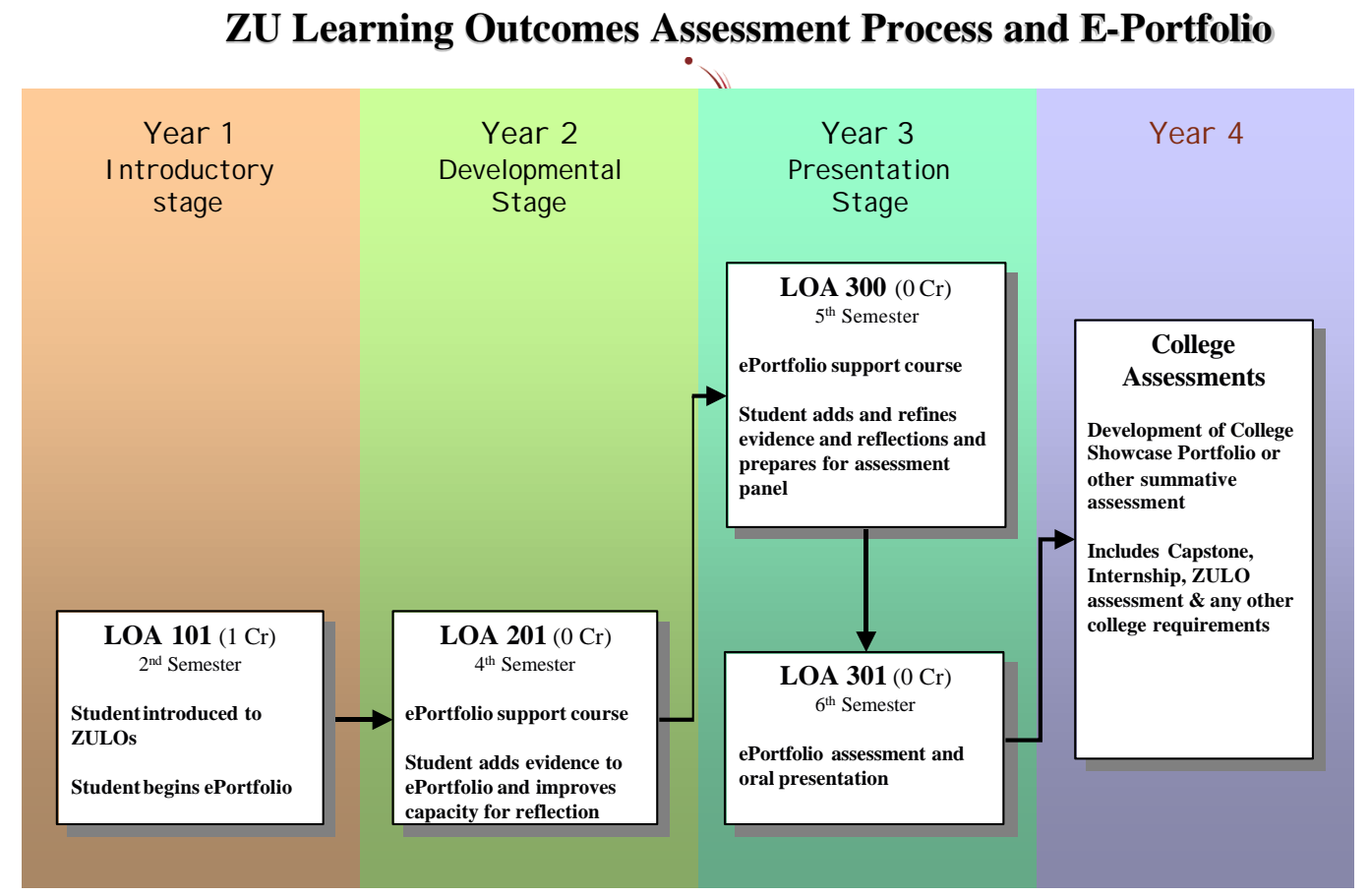

Figure 3. Learning Outcome Assessment Courses

\section{The Faculty Training as Assessors}

Faculty members at ZU are trained to teach and assess LO courses at various levels of the student's academic life as shown in Figure 3. Seminar faculty members teach introductory courses, LOA 101 and LOA 201 in year 1 and 2 respectively. Faculty members in the majors teach LOA 300 and LOA 301 during the third year. In order to teach LOA 300 levels, faculty is trained by attending a series of workshops provided by the CTLA. LOA 300 course is designed to help students collect best evidences of their work and develop an electronic portfolio. The LOA 301 course is designed to assess student's eportfolios and their understanding of the University learning outcomes. Only certified faculty can assess and provide to students in LOA 301.

\section{The Electronic Portfolio}

Students are expected to document their significant learning experiences. To facilitate this process, students take special courses to learn how to collect pieces of evidence selected from classroom project and out of class activities. Students document their achievement by creating an electronic portfolio reflecting their learning experiences

The electronic portfolio is a collection of students' work that:

- Allow students to demonstrate academic achievement and personal growth and record their progress over time.

- Allows them to see the relationships between educational experiences, curricular and extracurricular. 
- Represents some of the best samples of their work, as well as an explanation of how those samples demonstrate their achievement of the university's learning expectations.

Furthermore, students are required to write an essay to reflect on their learning experiences, in which they explain how they substantiate the level of achievement of a particular learning outcome.

Students are required to present an oral defense of their abilities in the ZU Learning Outcomes to an assessment panel. This assessment requires students to discuss three areas of their development in the ZU learning outcomes.

- A piece of evidence which represents their best work

- A reflection on the outcome achievements

- A statement of how they have satisfied the college requirements for the ZU learning outcomes for their major.

The assessment panel provides oral and written feedback to students regarding their developmental level in each ZULO and will produce a narrative report. The report will become part of the student's record and is forwarded to colleges. The colleges can then decide on how they wish to use this feedback in decisions regarding entry to internship.

\section{Learning Outcomes in Internship and Capstone Projects}

During their final baccalaureate year, students must successfully complete an internship and develop a capstone project. The capstone project serves as a culminating focal point, encouraging students to tie together the knowledge, skills and abilities they have developed during their learning experience at the university.

Students' abilities in the ZU Learning Outcome areas are assessed in connection with both the internship and capstone. In their internship, students must satisfy the employer's as well as faculty supervisor's requirements. In their capstone project, they must take responsibility for completing a major project in their chosen field to the satisfaction of their major program faculty. At the end of their internship, students make a final report in which they perform a reflection on their achievement of the learning outcomes and a critical review of their experience. This exercise may help students make better career decisions upon graduation.

It is difficult to keep up in today's fast-paced world. One of the major purposes of the capstone project is to develop students' awareness of the vital importance of life-long learning. Throughout the university's programs, students develop skills they will need in order to continue learning and to make good use of their knowledge, whatever future circumstance they may face. They are expected to reflect on their work, objectively assess their accomplishments, and continuously improve their performance.

Equipped with intellectual skills learned and experimented with during the capstone experience and which go far beyond the course-credit approach, university graduates are ready to envision the possibilities and seize the opportunities that will shape their future and the future of their nation. In the following section we show how the APM is used in the development of an Information System Curriculum.

\section{Using APM in Information System Curriculum}

The ZU College of Information systems developed a curriculum based on the APM. This curriculum is designed to reflect the UAE needs for graduates that are well prepared to enter the workforce and to assume their place of responsibility and leadership in the family, community and the nation. The goal of the College is to produce graduates having strong technology and communication skills as well as good understanding of business practices and work ethics. 


\section{A Novel Outcome-Based Educational Model}

In the Information Systems curriculum, five Major Learning Outcomes (MALOs) are identified, which form the basis of the curriculum. All course syllabi have to explicitly identify the course contribution to achieving the MALOs and the higher order learning outcomes (ZULOs). Furthermore, a web based common course syllabus (CCS) is used to facilitate the access of course content information, as well as the consistency and transparency of the syllabi.

The curriculum include foundation material in: Problem-solving, Object-Oriented paradigm, File Systems, Operating Systems, Systems Architecture, Mathematics for Computing, Computer Networking, and Technical Communication (Figure 4).

Furthermore, the curriculum includes independent study components that provide the students with the opportunity to gain in-depth knowledge of current information systems technologies, methods, and practices. There are two learning modes that have been incorporated into the IS curriculum, and these are: Guided self-learning mode and Guided Teamwork mode.

The proposed ZU APM is designed to continuously improve the curriculum and should provide students with the needed knowledge and skills that will help them succeed in this rapidly changing world.

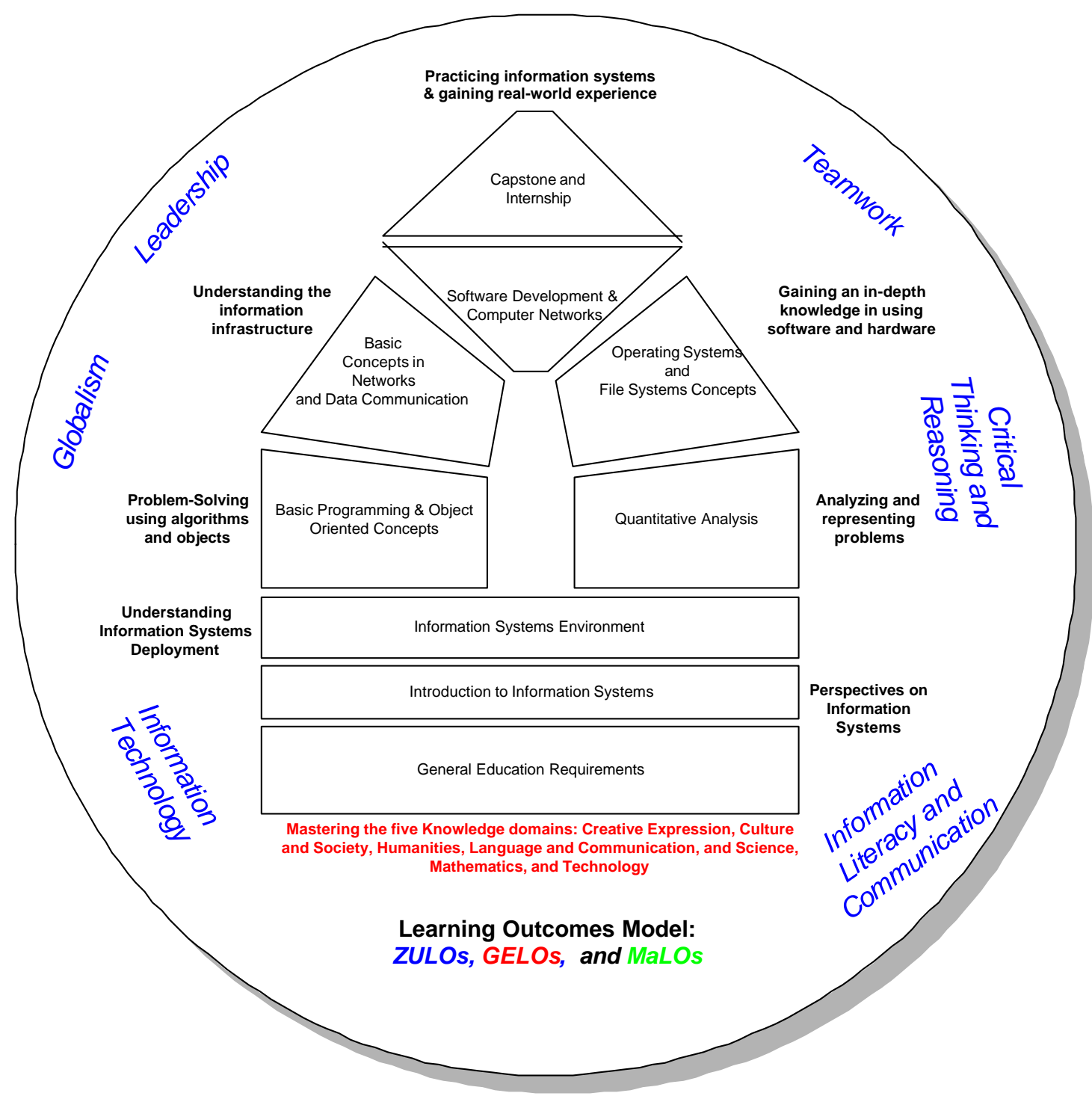

Figure 4. Learning Outcomes Overview 


\section{Conclusions}

A new concept for developing and assessing an outcome based educational model is proposed. This academic model responds well to challenges of a rapidly changing such as the UAE and is currently implemented at ZU. The framework that constitutes the model is composed of sets of well chosen learning outcomes (course embedded and higher-order learning outcomes), technology (laptop, wired campus), eportfolios, assessments and reflection, and learning communities. The learning outcomes are used at all stages of the students' academic life. These outcomes are derived from the university learning community's vision of the knowledge and skills that students need to acquire in order to be life-long learners and effective members of the society. Students develop electronic portfolios to demonstrate their academic achievements and record their progress over time. Furthermore, students reflect on their learning experiences. Assessment panels review the student work and provide feedback.

What makes ZU learning outcome assessment different from other traditional assessment protocols is the longitudinal, integrative and reflective nature of the portfolio experience. The electronic learning portfolios, in contrast to standard university assessments, requires students to see the connections between and among their learning experiences by aligning their evidence with the outcomes and reflecting about why the evidence shows their growing proficiency in ability.

Hence, the value of the students' academic experience is not only represented by how well students do in a specific course or by the grades that go on their transcripts, but rather, the true measure of their education is how what they learn empowers their further achievement.

It is too early to assert the effectiveness of this newly adopted academic model. The challenges that face the faculty members are numerous; some issues that need to be addressed are how to effectively integrate learning outcomes in courses, how to assess students in a way that will contribute to their learning experiences and how to shift the focus from input/lecturing to feedback/learning. Finally this new model is a dynamic model that will evolve with demands from the learning community and the country at large.

\section{References}

Academic Program Model (2002). Zayed University (www.zu.ac.ae).

Bouslama, F., Lansari, A., Al-Rawi, A., \& Abonamah, A. (2002). Assessing a new academic model using artificial neural networks. Proceedings of the 2002 IEEE International Conference on System, Man and Cybernetics, October 6-9, Hammamet, Tunisia, WA1P6.

Fitzpatrick, K. (1995, January). Leadership challenges of outcome-based education. Education Digest, 60, 13-16.

Furman, G. (1994). Outcome-based education and accountability. Education and Urban Society, 26 (4), 417-437.

Glatthorn, A. (1993). Outcome based education: reform and the curriculum process. Journal of Curriculum and Supervision 8, 334-363.

Greater Expectation: A new Vision for Learning as a Nation Goes to College. (2002). National Panel Report. Association of American Colleges and Universities (www.aacu.org).

Guskey, T. (1994, September). Defining the differences between outcome-based education and mastery learning. The School Administrator, 51, 34-37.

Kirk, D., \& Welborn, L. (1992, March). The impact of outcome-based education and the library media program. Colorado Libraries, 18, 5-9.

McNeir, G. (1993). Outcome-based education: Tools for restructuring. Oregon School Study Council Bulletin .

Rosovsky, H., \& Hartley, M. (2002). Evaluation and the academy: Are we doing the right thing? Grade inflation and letters of recommendation. American Academy of Arts \& Sciences.

Schwarz, G., \& Cavener, L. (1994). Outcome-based education and curriculum change: Advocacy, practice, and critique. Journal of Curriculum and Supervision, 9 (4), 326-338. 
Spady, W., \& Marshall, K. (1994, November). Light, not heat, on OBE. The American School Board Journal, 181, 29-33.
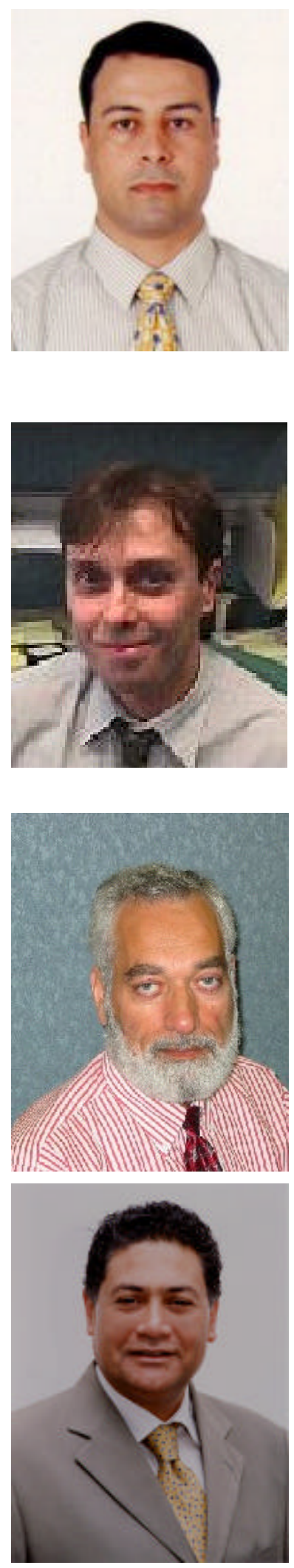

\section{Biographies}

Faouzi Bouslama received an MS in Electrical Engineering from Ibaraki University, Hitachi, Japan, in 1989, and PhD degree in Electronic Engineering from Shizuoka University, Hamamatsu, Japan in 1992. From 1992-1994, he was a Researcher at Toshiba Corporation, Tokyo, Japan. From 1994-2000, he was an Associate Professor, College of Information Systems, Hiroshima City University, Japan. He joined Zayed University, UAE, in 2000 as an Associate Professor at the College of Information Systems. His research interests include System modeling and control, Outcome-based education, Fuzzy logic, Neural networks, OCR systems, and Digital signal processing.

Azzedine Lansari received an MS in Biomedical Engineering from North Carolina State University (NCSU) in 1986 and a Ph.D. in Biomedical Engineering from NCSU in 1992. From 1990-1993 he was a research scientist at Computer Sciences Corporation and from 1993-1998 he worked as a project scientist for ManTech Environmental Technology. Currently he is an Assistant Professor in the College of Information Systems at Zayed University. His research interests include Systems modeling, Educational technology, and Curriculum design in information systems.

Akram Al-Rawi received an MS in electrical and electronics engineering from the University of Manchester in 1978, a PhD in electrical engineering from the University of Bath in 1981, and a second MS in electrical and computer engineering from the University of Missouri-Columbia in 1988. He received the IEE Crompton award for excellence in research in 1981. Akram has worked in several academic institutions of which the last two were the University of MissouriColumbia and Columbia College, MO, where he was a tenured Associate Professor of CIS until summer of 2000. In the fall of 2000, he joined Zayed University where currently he is a Professor in Information Systems.

\footnotetext{
Abdullah A. Abonamah received the B.S. degree in Computer Science from the University of Dayton in 1978, the M.S. degree in Computer Science and Engineering from Wright State University in 1982, and the PhD degree in Computer Science from the Illinois Institute of Technology in 1986. From 19861989 he was an Assistant Professor at the University of Wisconsin-Oshkosh. In 1989, he joined the Department of Mathematics and Computer Science at the University of Akron as an assistant professor and became an Associate Professor in 1993. Currently, Dr. Abonamah is a Professor and the director of ITI (Institute of Technological Innovation) at Zayed University.
} 